\title{
WILL THE "NAGOYA PROTOCOL ON ACCESS AND BENEFIT SHARING" PUT AN END TO BIOLOGICAL CONTROL?
}

\author{
J. C. VAN LENTEREN \\ Laboratory of Entomology, Wageningen University, P.O. Box 6, 6700AA, \\ Wageningen,The Netherlands; joop.vanlenteren@wur.nl
}

\begin{abstract}
SUMMARY
Biological control is one of the most environmentally safe and economically profitable pest management methods. Beneficial organisms used in biocontrol can be of native or exotic origin. As invasive species are being accidentally introduced at an ever-increasing rate, deliberate introductions of non-native biocontrol agents are often needed for the area-wide management of these invasive pests. However, recent regulations have delayed or prevented prospecting for new, non-native natural enemies. A first phase of regulation started in the 1980s and concerned the development of risk analyses for non-native species. At this time, as commercial biocontrol became popular and the number of species of biocontrol agents on the market quickly increased, many thought that risk analyses were needed to prevent non-experts importing and commercializing insufficiently studied organisms. However, implementation of (environmental) risk assessments for biocontrol agents has resulted in a slowdown in the use of new non-native natural enemies, and in higher project costs caused by the need to prepare elaborate application dossiers. These regulations were mainly aimed at preventing potential negative effects of releasing non-native biocontrol agents and, thus, in increasing confidence in this pest management method. The second phase of regulations started more recently and deals with the question "Who owns biological control agents?" At the Convention on Biological Diversity (CBD) in Rio de Janeiro (Brazil) in 1993, one of the three objectives formulated was "the fair and equitable sharing of the benefits arising out of the utilization of genetic resources". Biocontrol agents are such genetic resources. The Nagoya Protocol, a supplementary agreement to the CBD, provides a framework for the effective implementation of the fair and equitable sharing of benefits (i.e. the Access and Benefit Sharing (ABS) regulations) arising out of the utilization of genetic resources. Signatories of the Protocol are required to develop a legal framework to ensure access to genetic resources, benefit-sharing and compliance. Recent applications of CBD principles have already created barriers to collection and export of natural enemies for biocontrol research in several countries. If the Nagoya Protocol is widely applied, it may seriously interfere with searching for and application of biocontrol agents against invasive pests. Therefore, the International Organization for Biological Control (IOBC) first of all made an appeal to those involved in developing the legal framework for ABS, to design regulations that support the biocontrol sector by facilitating the exchange of biocontrol agents, including clear guidelines. Secondly, the IOBC also strongly recommended that biocontrol agents should be considered as a special case under the $\mathrm{CBD}$, by creating a non-financial ABS regime, mainly because classical biocontrol is a non-for-profit activity, and both developing and developed countries benefit from the use of the same biocontrol agents. Thirdly, as prospecting for new non-native natural enemies has currently been suspended if not terminated
\end{abstract} Development and Field Application, pp. 655-667. CRC Press, Boca Raton, Florida, USA. (C) 2021 IAEA 
in many countries due to $\mathrm{CBD}$ and $\mathrm{ABS}$ procedures, the IOBC prepared a best practices guide to assist the biocontrol community to demonstrate due diligence in complying with ABS requirements. The best practices guide includes a draft ABS Agreement for collection and study of biocontrol agents that can be used for scientific research and non-commercial release into nature by countries having signed the Nagoya Protocol. If many countries decide to implement the IOBC proposal for an agreement for collection and study of natural enemies, biocontrol might face a bright future.

Key Words: Biocontrol, pest management, beneficial organisms, invasive species, non-native natural enemies, risk assessment, Convention on Biological Diversity, International Organization for Biological Control, best practices guide for biological control

\section{INTRODUCTION}

Biological control (hereafter "biocontrol") - the use of an organism to reduce the population density of another organism - is one of the most environmentally safe and economically profitable pest management methods (Barratt et al. 2018). In biocontrol, parasitoids, predators, pathogens, herbivores and antagonists are used to reduce populations of pests, diseases and weeds (van Lenteren et al. 2018). These beneficial organisms can be native, but are also often non-native, particularly when the pest (defined by FAO (2017) as including diseases, weeds and animal pests) is of nonnative origin.

Invasive species are being introduced accidentally around the world at an increasing rate, caused by increasing travel, trade, and tourism, have led and will continue to result in the introduction of pests of foreign origin (Bacon et al. 2012; Seebens et al. 2017). In contrast, deliberate introductions of non-native biocontrol agents have resulted in permanent control of many pests, while having caused remarkably few problems (Cock et al. 2010). It is nowadays often required in biocontrol to perform a risk assessment for new agents prior to obtaining approval for introduction and release (van Lenteren et al. 2006). Until a few years ago, prospecting for new, non-native natural enemies after accidental introductions of non-native pests was possible, and usually occurred with the consent of the country where prospecting took place (Cock et al. 2010).

The Access and Benefit Sharing (ABS) requirement of the Nagoya Protocol (SCBD 2011) has brought about an almost complete stop to natural enemy exploration programmes, whereas introduction of non-native pests is continuing, resulting in eradication projects with a frequent input of chemical pesticides causing negative effects on biodiversity, the environment and human health (Suckling et al., this volume). Although biocontrol researchers recognize the importance of a proper ABS procedure, the current state of affairs is highly bureaucratic and does not acknowledge the mutual benefits of biocontrol projects for countries providing and receiving beneficial organisms, projects that have been carried out for more than 100 years (Cock et al. 2010).

Biocontrol does not fall under bioprospecting ("the search for plant and animal species from which medicinal drugs and other commercially valuable compounds can be obtained") or biopiracy ("bioprospecting without permission of the country that owns the genetic resources and which exploits plant and animal species by claiming patents to restrict their general use"). Bioprospecting and biopiracy are often concerned with products that can be protected with intellectual property rights in order 
to generate monetary profits for companies (e.g. pharmaceuticals), which is not the case with beneficial organisms because they cannot be patented. Up until now, many biologists, including taxonomists and biocontrol practitioners, are still unaware of the implications of the Nagoya Protocol under the Convention on Biological Diversity (CBD) for their field of research.

In this chapter, I will first summarize the achievements of biological control, then describe the first phase of regulations related to biocontrol, next explain the Nagoya Protocol and, finally, discuss the consequences of the Nagoya Protocol for the practice of biocontrol.

\section{ACHIEVEMENTS OF BIOLOGICAL CONTROL}

Biocontrol has been in use for at least 2000 years, but modern use started at the end of the $19^{\text {th }}$ century (DeBach 1964; van Lenteren and Godfray 2005). Four different types of biological control are usually distinguished: natural, conservation, classical, and augmentative biocontrol (Cock et al. 2010):

- Natural biocontrol is an ecosystem service (Millennium Ecosystem Assessment 2005) whereby pest organisms are reduced by naturally occurring beneficial organisms. It occurs in all of the world's ecosystems without any human intervention and is the greatest contribution of biocontrol to agriculture when expressed in economic terms (Waage and Greathead 1988; Cock et al. 2012).

- Conservation biocontrol consists of human activities protecting and stimulating the performance of naturally occurring natural enemies. This form of biological control is currently receiving a lot of attention for pest control (Barratt et al. 2018; Heong et al. this volume).

- In classical biocontrol (CBC), natural enemies are collected in the area of origin of the pest and then released in areas where the pest invaded, and when successfully established, results in area-wide and permanent pest control providing large economic benefits (Cock et al. 2010, 2016a; Barratt et al. 2018).

- In augmentative biocontrol (ABC), native or non-native natural enemies are massreared for repeated release in large numbers to obtain immediate control of pests, usually in seasonal crops (van Lenteren et al. 2018).

For $\mathrm{CBC}$, recent reviews provide detailed information about successes. Cock et al. $(2010,2016 \mathrm{~b})$ present achievements of $\mathrm{CBC}$ of insect pests with insect natural enemies. One of the many striking examples of how successful $\mathrm{CBC}$ can be is that of a scale pest, Icerya purchasi Maskell (Hemiptera: Monophlebidae). This citrus pest was accidentally introduced in the 1880s in California (USA). Chemical control was impossible and citrus production was expected to have to be terminated. However, entomologists identified the country of origin of the pest (Australia), collected its natural enemies, shipped them to California for release in citrus orchards. Within a few years the natural enemies, including the Vedalia beetle Rodolia cardinalis (Mulsant) (Coleoptera: Coccinellidae), spread over the citrus area and saved the citrus industry in California and later in many other scale-infested citrus areas. 
The Rodolia beetle has already controlled the Icerya scale pest on citrus for more than 100 years in more than 50 countries without causing any negative side effect (Cock et al. 2010). Cock et al. (2010, 2016b) provide many other examples of successful CBC of arthropod pests, while Winston et al. (2014) and Shaw and Hatcher (2017) summarize numerous examples of CBC of weeds.

By the end of 2010, 6158 introductions, using 2384 different species of natural enemies against 588 pest species had been made in 148 countries, of which 2007 (32.6 $\%)$ led to establishment, and $620(10.1 \%)$ resulted in satisfactory control of $172(29.3$ $\%$ ) different pest species. The $10 \%$ success rate can be considered as very high, particularly when compared with chemical control where 1 out of $20000-1000000$ candidate compounds may kill pest insects. Not only are the success rates in CBC impressive, but also the benefit-cost ratios are striking and in the order of 20:1-1000:1 (Cock et al. 2010; Barratt et al. 2018). These high benefit-cost ratios can be explained by the fact that once a good natural enemy has been found, pest control is permanent, unless it is disrupted by use of chemical pesticides that kill the biocontrol agent.

Cock et al. (2016b) mentioned that the number of CBC introductions has decreased each decade during the past 40 years. An important factor in the decrease during the past two decades is the development and implementation of the Nagoya Protocol (SCBD 2011).

Van Lenteren et al. (2018) recently summarized successes of $A B C$, which has been applied for more than 120 years in several cropping systems and is now estimated to be used on 30 million ha worldwide. Today, ABC is applied in many areas of agriculture, such as fruit and vegetable crops, cereals, maize, cotton, sugarcane, soybeans, grapes and many greenhouse crops. Since the 1970s, ABC has moved from a cottage industry to professional research and production facilities, as a result of which many efficient agents have been identified, quality control protocols, mass production, shipment and release methods matured, and adequate guidance for farmers and extension agents has been developed (van Lenteren 2003; Ravensberg 2011).

About 350 species of invertebrate natural enemies, as well as 209 microbial strains from 94 different species are currently commercially produced (van Lenteren et al. 2018). Recent successes of ABC with arthropod natural enemies include the virtually complete replacement of chemical insecticides by predators (mites and hemipterans) to control thrips and whiteflies on sweet peppers in greenhouses in Spain (Calvo et al. 2012), and the use of hemipteran predators to control new invasive pests like the South American tomato moth Tuta absoluta (Meyrick) (Lepidoptera: Gelechiidae) (Urbaneja et al. 2012). Another recent ABC success deals with the use of microbial control agents. The invasion of the cotton bollworm Helicoverpa armigera (Hübner) (Lepidoptera: Noctuidae) into Brazil in 2012 caused tremendous damage to corn, cotton, and soybeans, because insecticides were not effective due to pest resistance, or were simply not available. Emergency approvals of the entomopathogenic bacterium Bacillus thuringiensis Berliner (Bacilliaceae) and baculovirus products provided farmers with the only effective control method at the time (J. R. P. Parra, personal communication). 
From 1900 to 1959 only exotic biocontrol agents were used in $\mathrm{ABC}$ in Europe. After 1960, the use of native biocontrol agents in ABC increased. Due to implementation of various regulations, and particularly as a result of the application of the Nagoya Protocol, prospecting for non-native natural enemies has practically come to a standstill and a very clear shift in use of native natural enemies has taken place since 2000 (Fig. 1).

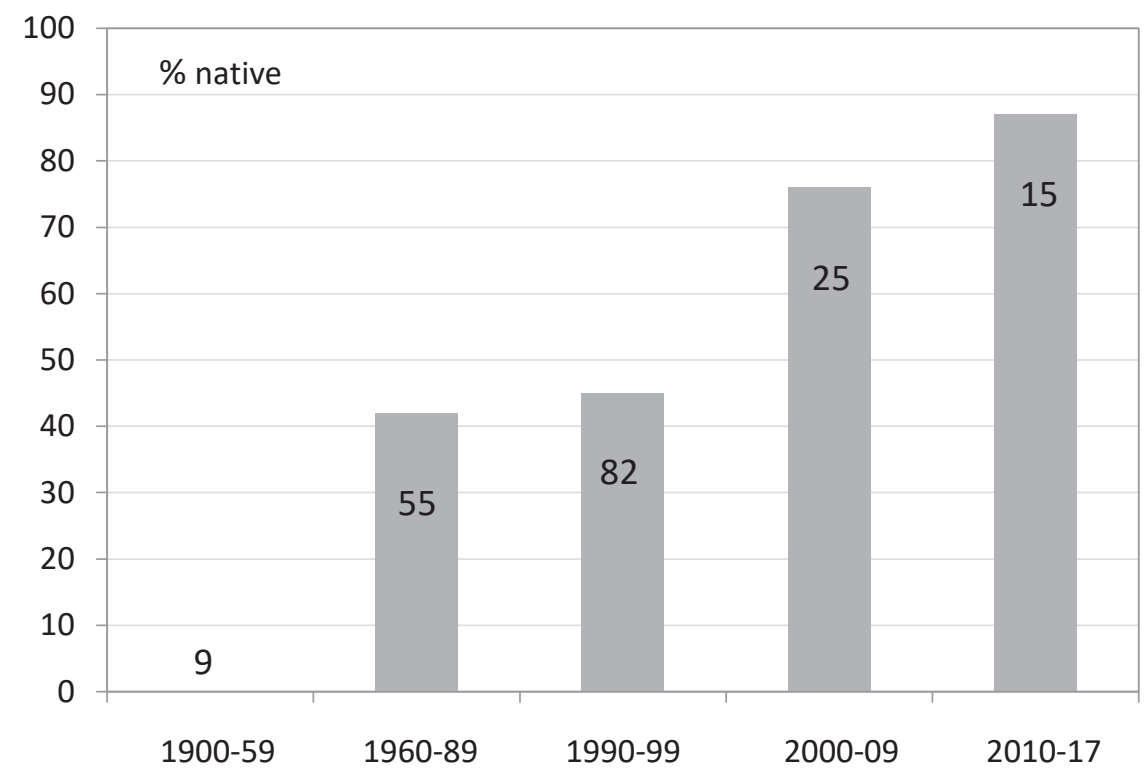

Figure 1. Percentage of new native natural enemies introduced on the European market for augmentative biocontrol through time (in columns; zero between 1900-1959). Total introductions per period are given in numbers (based on tables and supplementary material in van Lenteren et al. 2018).

\section{FIRST PHASE OF REGULATION CONCERNING IMPORT AND RELEASE OF NATURAL ENEMIES}

During the first century of "modern" biocontrol $(1880$ - 1980) few regulations existed concerning risk associated to insect biocontrol agents. However, most researchers in this field of ecology were well aware of the risk of importing certain types of natural enemies, particularly those that showed polyphagous predation behaviour and were, thus, often not only eating pests, but also other organisms (Boller et al. 2006).

In weed biocontrol this resulted in the so-called "centrifugal evaluation method" of potential biocontrol agents, whereby first species taxonomically closely related to the pest are tested and, if one or more of these are eaten by the herbivore, the next circle of related species is tested, and so on (Wapshere 1974). 
Thorough risk analyses for natural enemies of arthropod pests were developed much later than for weed biocontrol, and pre-release environmental risk analyses for these natural enemies have only been applied since the 1980s. The reason might be that very few problems had been reported concerning negative effects of releases of non-native invertebrates for biological control (i.e. Follett and Duan 2000; Lynch et al. 2001). However, when ABC became popular in the 1980s and the number of species of biocontrol agents on the market quickly increased (see Fig. 2 in van Lenteren 2012), the need for pre-release environmental risk assessments for new natural enemies was realized, partly because non-experts also started to collect, import and release new biocontrol agents (Bigler et al. 2006).

In 2006, 20 countries had already implemented regulations for the import and release of biocontrol agents and many other countries followed. Initially, the Food and Agriculture Organization of the United Nations (FAO) together with the Centre for Agriculture and Bioscience International (CABI) and the International Organization for Biological Control (IOBC 2019) designed a code of conduct for import and release of biocontrol agents, but this non-compulsory guideline did not contain methods for risk assessment (FAO 1996, 2005). Next, IOBC took the initiative to develop standard methods that could be applied to produce data for risk assessment, as well as developing risk assessment methods including practical guidance on how to measure and evaluate effects leading to conclusions about risks and benefits of biocontrol agents under consideration, which are described in Bigler et al. (2006), van Lenteren et al. (2006), and many other papers.

The danger of current risk evaluations is that they only concentrate on possible negative effects caused by biocontrol agents, while not paying attention at the same time to:

1. The socio-economic effects of the damage brought about by the pest

2. The negative health and environmental effects produced by chemical pesticides, and

3. The many potential benefits from biocontrol (van Lenteren and Loomans 2006; Heimpel and Cock 2018).

Environmental risk assessments are now being used by a growing number of countries. Most risk assessments are characterized by the following general elements:

1. Characterization of natural enemy, i.e. information about the taxonomic status of the agent and its biology.

2. Human health risks, i.e. information about human health risks that is often much easier to obtain than for chemical pesticides, particularly for invertebrate natural enemies.

3. Environmental risks, i.e. collection of information on the environmental risks is usually the most time consuming aspect of the risk assessment and consists, amongst other things, of information on potential for establishment in the country of introduction, the prey/host range of the natural enemy (including tests of unrelated, beneficial, and rare and culturally valued species), dispersal capacity, and potential direct and indirect non-target effects that might be caused in the country of introduction. As collection of information for this element is generally very costly, a stepwise procedure for evaluation has been proposed, in order to be able to quickly eliminate obviously risky species (see Fig. 3 in van Lenteren et al. 2006). 
4. Efficacy, i.e. a very different approach is proposed to obtain information about efficacy as compared with the one usually followed for chemical pesticides. Biocontrol agents are almost without exception used in integrated pest management (IPM) programmes, and therefore the efficacy does not necessarily have to be in the order of $95-100 \%$. Any significant reduction in pest numbers by the biocontrol agents contributes to the overall pest management, and, thus, it suffices to show that an efficacious natural enemy is capable of significantly reducing pest populations.

The routine implementation of environmental risk assessments for biocontrol agents has resulted in a slowdown of newly marketed non-native $\mathrm{ABC}$ biocontrol agents (Figs. 1 and 2) and introductions for CBC (Fig. 3). The preparation of elaborate application dossiers has also resulted in higher developmental costs, but it did not bring prospecting for new non-native species to an end.

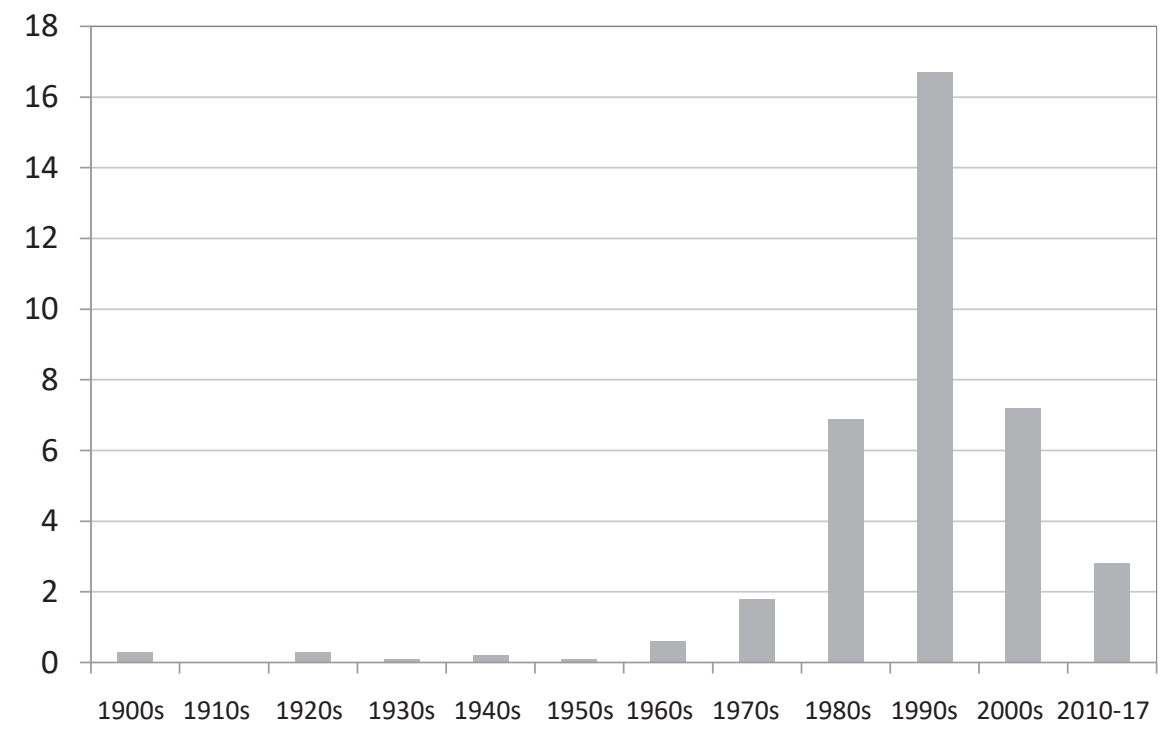

Figure 2. Average number of newly marketed natural enemy species per year within a decade for augmentative biocontrol (based on tables and supplementary material in van Lenteren et al. 2018).

The main problem in some parts of the world is a lack of harmonization of regulations. In Europe, for example, some countries apply no regulations at all, while in other countries they vary from rather easy to extremely complicated, and in our experience, the less expertise a country has in the field of biocontrol, the longer the evaluation of new biocontrol agents takes due to over-regulation. 
Still, many biocontrol specialists consider it fair that risks of releasing non-native organisms need to be evaluated prior to import, that careful evaluation of risk and benefits will maintain or strengthen the excellent reputation of this sustainable and environment-friendly form of pest management and, that it in the end will result in even more confidence in biocontrol.

The dramatic decline in newly marketed natural enemies since 2000 is not the result of a decrease in the sale of biocontrol agents or of the area on which the agents are applied. On the contrary, the $\mathrm{ABC}$ market showed an annual increase of sales of 10\% until 2005 and more than 15\% per year since 2005 (Dunham 2015).

Fig. 3 shows the average number of natural enemy introductions per year within a certain decade for CBC. Cock et al. 2016b described an introduction as a unique combination of a biocontrol agent, target country and first year of introduction. Introduction of a certain species of natural enemy into five different countries is thus considered as five introductions. Since the start of CBC in the 1880 s, a steady increase in number of introductions can be observed, with two periods showing lower numbers of introductions due to WWI and II.

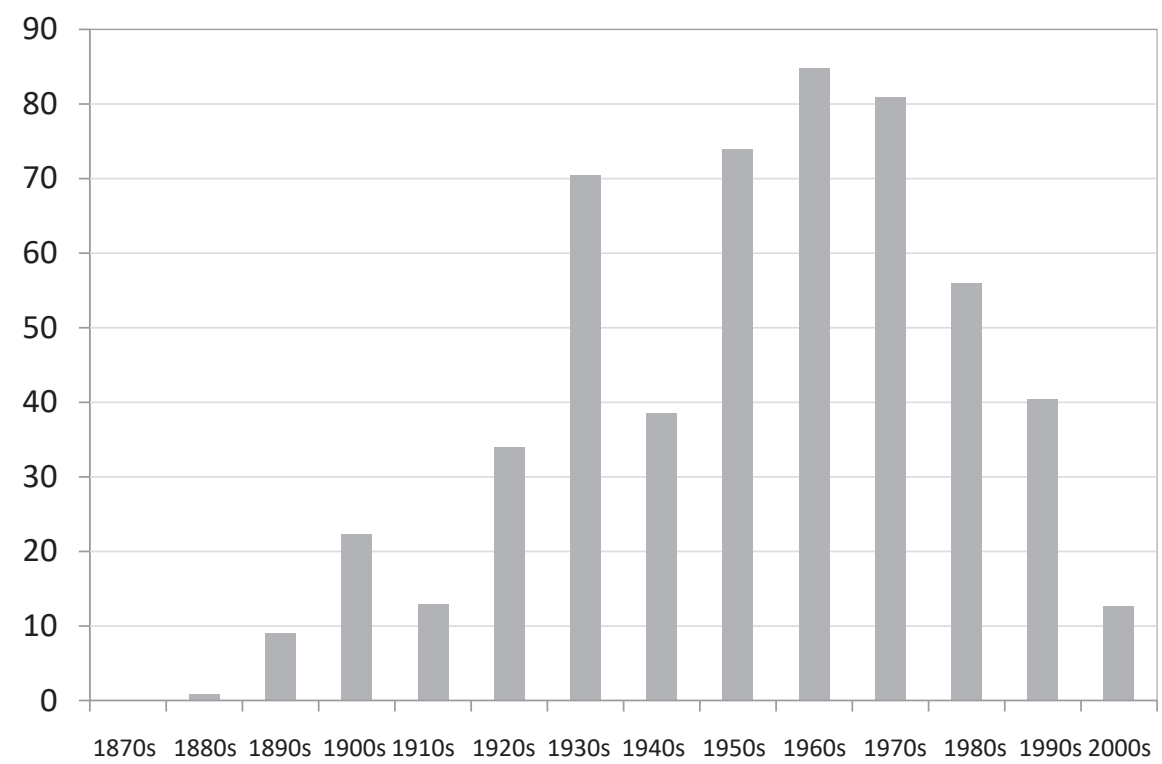

Figure 3. Average number of natural enemy introductions per year within a decade for classical biocontrol (based on Figure 1 in Cock et al. 2016 b and data provided by M. Cock).

Then, starting in the 1980s the number of introductions decreases. According to Cock et al. 2016b this was caused by a growing risk-averse culture in many countries, which resulted in the need for more in-depth studies for non-target and environmental impact, and more recently, by the application of principles resulting from the Convention on Biological Diversity, which are discussed in the next Section. 


\section{SECOND PHASE OF REGULATIONS CONCERNING ACCESS AND BENEFIT SHARING}

The first phase of regulations was aimed at improving biocontrol, preventing potential negative effects, and increasing confidence. The second phase of regulations has nothing to do with the science of biocontrol, but deals with the question "Who owns biological control agents?" This Section is based on recent papers written by Cock et al. (2010), Mason et al. (2018), as well as discussions among members of IOBC Global Commission on Access and Benefit Sharing (ABS 2019).

At the Rio CBD (CBD 1993) three objectives were formulated: conservation of biological diversity, sustainable use of its components, and fair and equitable sharing of the benefits arising from the utilization of genetic resources. The CBD is an international framework convention, and its provisions are binding for its contracting parties. However, the CBD cannot prescribe how decisions are to be implemented by the parties since different countries have different legal structures. Countries have sovereign rights over their biological resources, and agreements governing the access to these resources and the sharing of the benefits arising from them should be established and agreed between the parties involved.

In 2002, the Conference of Parties (COP) to the CBD adopted the 'Bonn Guidelines on Access to Genetic Resources and Fair and Equitable Sharing of Benefits Arising out of their Utilization - Decision VI/24' (SCBD 2002). Genetic resources are defined as genetic material, i.e. material containing functional units of heredity that is of actual or potential value (CBD Art. 2), so this includes all biocontrol agents taken from one country (provider) to another (recipient) (Cock et al. 2010). The value of the genetic resources need not be commercial (i.e. monetary) but may be scientific or academic in nature. As the CBD definition also includes the potential value of such resources, in effect all genetic material falls under the provisions of the ABS system (Cock et al. 2010).

The Nagoya Protocol came into force in October 2014 and is a supplementary agreement to the CBD that provides a framework for the effective implementation of the fair and equitable sharing of benefits arising from the utilization of genetic resources (SCBD 2011). Signatories and countries acceding to the Nagoya Protocol are required to develop a legal framework to ensure access to genetic resources, benefit-sharing and compliance. The biocontrol community needs to comply with ABS regulations arising under the Nagoya Protocol (Mason et al. 2018). The ABS is a potentially serious threat to the use of biocontrol for two important reasons:

1) the necessity of agreements governing access to genetic resources, and

2) sharing of benefits arising from their use between the parties involved.

Recent applications of CBD principles have already created barriers to collect and export natural enemies for biocontrol research and application in several countries. If the Nagoya Protocol is widely applied, it may seriously interfere with searching for and application of biocontrol agents against invasive pests. Therefore, the IOBC Global Commission on Biological Control and Access and Benefit Sharing first of all made an appeal for ABS regulations that support the biocontrol sector by facilitating the exchange of biocontrol agents, including clear guidelines (ABS 2019). These guidelines should also include fast track procedures for finding and applying biocontrol agents in case of humanitarian or emergency situations, such as after 
unintentional export of an invasive pest to a new area. The IOBC Commission also strongly recommended that biocontrol agents should be considered as a special case with respect to an ABS regime under the CBD (Cock et al. 2010) by creating a nonfinancial ABS regime for classical biocontrol, as countries providing biocontrol agents are also users of the technology, in view that:

1) biocontrol is widely used in both developing and developed countries often with the same biocontrol agents,

2) biocontrol agents cannot be patented,

3) collected information about biocontrol agents is shared publicly,

4) indigenous/traditional knowledge has not been relevant, and

5) the social benefits of biocontrol (such as increase of environmental and public health, reduction in pesticide use and costs of crop production), are a public good (Cock et al. 2010).

As prospecting for new non-native natural enemies has currently been suspended, if not terminated due to $\mathrm{CBD}$ and $\mathrm{ABS}$ procedures (or lack of procedures) in many countries, the IOBC Commission prepared a best practices guide to assist the biocontrol community to demonstrate due diligence in complying with ABS requirements, which should include the following components outlined in Mason et al. (2018): (1) collaborations to facilitate information exchange about what biocontrol agents are available and where they may be obtained, (2) knowledge sharing through freely available databases that document successes (and failures), (3) cooperative research to develop capacity in source countries, and (4) transfer of production technology to provide opportunities for small-scale economic activity.

Within the IOBC best practice guide for exchange of biocontrol genetic resources, the section concerning gaining access to biocontrol agents is of particular importance, and the IOBC Commission designed a draft ABS agreement for collection and study of biocontrol agents that can be used for scientific research and non-commercial release into nature by countries having signed the Nagoya Protocol. The IOBC Commission also proposed conditions under which biocontrol agents can be provided or should not be provided for countries where ABS regulations are not restrictive or do not exist. Details of the draft IOBC ABS agreement and the conditions can be found in Appendix 1 and 2 in Mason et al. (2018).

The purpose of the agreement is to set out the conditions for the use of naturally occurring biocontrol agent genetic resources, any associated traditional knowledge (TK), and the sharing of resulting benefits between the parties concerned in accordance with the CBD. The agreement is designed to promote non-commercial activities, such as research in taxonomy, ecology, and genetics, and to foster conservation and the environmentally sound and sustainable use of biocontrol agents. The objective of the agreement is to provide a sound basis for cooperation, transparency, communication and trust between the parties, taking into account the concerns of both providers and users of biocontrol agents. The agreement is based on prior informed consent and mutually agreed terms issued beforehand by the provider to the user for the access to the biocontrol agents, and specifies the terms for access to biocontrol agents, their utilization, their possible transfer to third parties and for sharing the benefits resulting from their utilization. 
The IOBC will use this document to negotiate the design of regulations that support the biocontrol sector by facilitating the exchange of biocontrol agents with $\mathrm{CBD}$, and encourages those involved in the practice of biocontrol to follow the IOBC best practice guide for exchange of biocontrol genetic resources as published in Mason et al. (2018).

\section{THE FUTURE OF BIOLOGICAL CONTROL IN LIGHT OF THESE REGULATIONS}

As explained above, the first phase of regulations was mainly aimed at preventing potential negative effects of release of non-native biocontrol agents and, thus, in increasing confidence in this pest management method. These first phase regulations have led to slower development of and higher costs to implement programmes that use new biocontrol agents, as well as a change in biocontrol approaches by first evaluating native natural enemies when a new pest arrives.

The second phase of regulation relates to implementation of the Nagoya Protocol and is having a much more drastic effect on the science of biocontrol. Although some countries have declined to place restrictions on access to their genetic resources for non-commercial research, including biological control, others have enacted legislation. However, many countries have yet to enact legislation and set up regulatory bodies, so that procedures are not in place to make decisions.

Prospecting for new natural enemies has been greatly reduced, biocontrol researchers risk imprisonment in some countries when collecting species, and the bureaucratic procedures to establish an ABS agreement are so unclear and timeconsuming that none has been realized to date. This is a very unwelcome development for both developing and developed countries because a clean, safe and sustainable form of pest management may be replaced by environmentally polluting and health threatening chemical pesticides.

Moreover, the current state of affairs concerning ABS are creating serious risks when accidentally exported pests, disease and weeds invade new regions in the world, because their naturally occurring biocontrol agents in their country of origin can no longer be studied, imported and released in recently invaded areas.

Hopefully the IOBC proposal for an agreement for collection and study of biocontrol agents will be embraced and implemented by biocontrol scientists in many countries as well as by $\mathrm{CBD}$, and soon result in renewed activities in both classical and augmentative biocontrol based on exchange of non-native biocontrol agents.

\section{ACKNOWLEDGEMENTS}

Barbara Barratt (AgResearch Invermay, Mosgiel, New Zealand), Jacques Brodeur (Institut de Recherche en Biologie Végétale, Université de Montréal, Montréal, Canada), Matthew Cock (CABI, Egham, UK), and Peter Mason (Agriculture and Agri-Food Canada, Ottawa, Canada) are thanked for reading and improving this chapter. 


\section{REFERENCES}

(ABS) Commission on Biological Control and Access and Benefit Sharing. 2019. International Organization for Biological Control (IOBC).

Bacon, S. J., S. Bacher, and A. Aebi. 2012. Gaps in border controls are related to quarantine alien insect invasions in Europe. PLoS One 7(10): e47689.

Barratt, B. I. P., C. V. C. Moran, F. Bigler, and J. C. van Lenteren. 2018. The status of biological control and recommendations for improving uptake for the future. BioControl 63: 155-167.

Bigler, F., D. Babendreier, and U. Kuhlmann. 2006. Environmental impact of invertebrates for biological control of arthropods: Methods and risk assessment. CABI Publishing, Wallingford, Oxon, UK. 288 pp.

Boller, E. F., J. C. van Lenteren, and V. Delucchi. 2006. International Organization for Biological Control of Noxious Animals and Plants (IOBC): History of the first 50 years $(1956-2006)$. Ponsen \& Looijen. Wageningen, The Netherlands.

Calvo, F. J., K. Bolckmans, and J. E. Belda. 2012. Biological control-based IPM in sweet pepper greenhouses using Amblyseius swirskii (Acari: Phytoseiidae). Biocontrol Science and Technology 22 1398-1416.

Cock, M. J. W., J. C. van Lenteren, J. Brodeur, B. I. P. Barratt, F. Bigler, K. Bolckmans, F. L. Cônsoli, F. Haas, P. G. Mason, and J. R. P. Parra. 2010. Do new access and benefit sharing procedures under the Convention on Biological Diversity threaten the future of biological control? Biocontrol 55: 199-218.

Cock, M. J. W., J. C. Biesmeijer, R. J. C. Cannon, P. J. Gerard, D. Gillespie, J. J. Jiménez, P. M. Lavelle, and S. K. Raina. 2012. The positive contribution of invertebrates to sustainable agriculture and food security. CAB Reviews: Perspectives in Agriculture, Veterinary Science, Nutrition and Natural Resources 7(43): 1-27.

Cock, M. J. W., R. K. Day, H. L. Hinz, K. M. Pollard, S. E. Thomas, F. E. Williams, A. B. R. Witt, and R. H. Shaw. 2016a. The impacts of some classical biological control successes. CAB Reviews: Perspectives in Agriculture, Veterinary Science, Nutrition and Natural Resources 10(42): 1-58.

Cock, M. J. W., S. T. Murphy, M. T. K. Kairo, E. Thompson, R. J. Murphy, and A. W. Francis. 2016b. Trends in the classical biological control of insect pests by insects: An update of the BIOCAT database. BioControl 61: 349-363.

(CBD) Convention on Biological Diversity. 1993. Convention on Biological Diversity (with annexes). Concluded at Rio de Janeiro on 5 June 1992. United Nations - Treaty Series 1760(30619): 142-382.

DeBach, P. 1964. Biological control of insect pests and weeds. Chapman and Hall, London, UK. 844 pp.

Dunham, W. C. 2015. Evolution and future of biocontrol. Paper presented at the 10th Annual Biocontrol Industry Meeting (ABIM), October 20th, Basel, Switzerland.

(FAO) Food and Agriculture Organization of the United Nations. 1996. Code of conduct on the import and release of biological control agents. International Standards for Phytosanitary Measures No. 3. International Plant Protection Convention. FAO, Rome, Italy.

(FAO) Food and Agriculture Organization of the United Nations. 2005. Guidelines for the export, shipment, import and release of biological control agents and other beneficial organisms. International Standards for Phytosanitary Measures No. 3. International Plant Protection Convention. FAO, Rome, Italy.

(FAO) Food and Agriculture Organization of the United Nations. 2017. Glossary of phytosanitary terms. International Standards for Phytosanitary Measures No. 5. International Plant Protection Convention. FAO, Rome, Italy.

Follett, P. A., and J. J. Duan (eds.). 2000. Non-target effects of biological control. Springer Science+Business Media, LLC, New York, NY, USA. 316 pp.

Heimpel, G., and M. J. W. Cock. 2018. Shifting paradigms in the history of classical biological control. BioControl 63: 27-37.

(IOBC) International Organization for Biological Control / Organisation Internationale de Lutte Biologique (OILB). 2019. http://www.iobc-global.org

Lynch, L. D., H. M. T. Hokkanen, D. Babendreier, F. Bigler, G. Burgio, Z. H. Gao, S. Kuske, A. J. M. Loomans, I. Menzler-Hokkanen, M. B. Thomas, M. G. Tommasini, J. K. Waage, J. C. van Lenteren, and Q. Q. Zeng. 2001. Indirect effects in the biological control of arthropods with arthropods, pp. 99-125. In E. Wajnberg, J. C. Scott, and P. C. Quimby (eds.), Evaluating indirect ecological effects of biological control. CABI Publishing, Wallingford, Oxon, UK. 
Mason, P. G., M. J. W. Cock, B. I. P. Barratt, J. Klapwijk, J. C. van Lenteren, J. Brodeur, K. A. Hoelmer, and G. E. Heimpel. 2018. Best practices for the use and exchange of invertebrate biological control genetic resources relevant for food and agriculture. BioControl 63: 149-154.

Millennium Ecosystem Assessment. 2005. Ecosystems and human well-being: Synthesis. World Resources Institute. Island Press, Washington, DC, USA. 137 pp.

Ravensberg, W. J. 2011. A roadmap to the successful development and commercialization of microbial pest control products for control of arthropods. Springer, Dordrecht, The Netherlands. 383 pp.

(SCBD) Secretariat of the Convention on Biological Diversity. 2002. Bonn guidelines on access to genetic resources and fair and equitable sharing of the benefits arising out of their utilization. Convention on Biological Diversity, Montreal, Canada.

(SCBD) Secretariat of the Convention on Biological Diversity. 2011. Nagoya protocol on access to genetic resources and the fair and equitable sharing of benefits arising from their utilization to the Convention on Biological Diversity: Text and annex. Convention on Biological Diversity, Montreal, Canada.

Seebens, H., T. M. Blackburn, E. E. Dyer, P. Genovesi, P. E., Hulme, J. M. Jeschke, S. Pagad, P. Pysek, M. Winter, M. Arianoutsou, S. Bacher, B. Blasius, G. Brundu, C. Capinha, L. CelestiGrapov, W. Dawson, S. Dullinger, N. Fuentes, H. Jaeger, J. Kartesz, M. Kenis, H. Kreft, L. Kuehn, B. Lenzner, A. Liebhold, A. Mosena, D. Moser, M. Nishino, D. Pearman, J. Pergl, W. Rabitsch, J. Rojas-Sandoval, A. Roques, S. Rorke, S. Rossinelli, H. E. Roy, R. Scalera, S. Schindler, K. Stajerova, B. Tokarska-Guzik, M. van Kleunen, K. Walker, P. Weigelt, T. Yamanaka, and F. Essl. 2017. No saturation in the accumulation of alien species worldwide. Nature Communications 8 (14435): 1-9.

Shaw, R. H., and P. E. Hatcher. 2017. Weed biological control, pp. 215-243. In Hatcher, P. E. and R. J. Froud-Williams (eds.), Weed research: Expanding horizons. Wiley, UK.

Urbaneja, A., J. Gonzalez-Cabrera, J. Arno, and R. Gabarra. 2012. Prospects for the biological control of Tuta absoluta in tomatoes of the Mediterranean basin. Pest Management Science 68: 1215-1222.

van Lenteren, J. C. (ed.). 2003. Quality control and production of biological control agents: Theory and testing procedures. CABI Publishing, Wallingford, Oxon, UK.

van Lenteren, J. C. 2012. The state of commercial augmentative biological control: Plenty of natural enemies, but a frustrating lack of uptake. BioControl 57: 71-84.

van Lenteren, J. C., and H. C. J. Godfray. 2005. European science in the enlightenment and the discovery of the insect parasitoid life cycle in The Netherlands and Great Britain. Biological Control 32: 12-24.

van Lenteren, J. C., and A. J. M. Loomans. 2006. Environmental risk assessment: Methods for comprehensive evaluation and quick scan, pp. 254-272. In F. Bigler, D. Babendreier, U. Kuhlmann (eds.), Environmental impact of invertebrates for biological control of arthropods: Methods and risk assessment. CABI Publishing, Wallingford, Oxon, UK.

van Lenteren, J. C., J. Bale, F. Bigler, H. M. T. Hokkanen, and A. J. M. Loomans. 2006. Assessing risks of releasing exotic biological control agents of arthropod pests. Annual Review of Entomology 51: 609-634.

van Lenteren, J. C., K. Bolckmans, J. Köhl, W. Ravensberg, and A. Urbaneja. 2018. Biological control using invertebrates and microorganisms: Plenty of new opportunities. BioControl 63: 39-59.

Waage, J. K., and D. J. Greathead. 1988. Biological control: Challenges and opportunities. Philosophical Transactions Royal Society London Series B 318: 111-128.

Wapshere, A. J. 1974. A strategy for evaluating the safety of organisms for biological weed control. Annals of Applied Biology 77: 201-211.

Winston, R. L., M. Schwarzländer, H. L. Hinz, M. D. Day, M. J. W. Cock, and M. H. Julien (eds.). 2014. Biological control of weeds: A world catalogue of agents and their target weeds, 5th edition. USDA Forest Service, Forest Health Technology Enterprise Team, Morgantown, West Virginia, USA. $838 \mathrm{pp}$. 